\title{
FORMUALTION AND DEVELOPMENT OF MUCOADHESIVE SUSTAINED RELEASE BUCCAL TABLETS AND PATCHES OF 5-FLUOROURACIL USING DIFFERENT POLYMERS
}

\author{
NITIN GAWAI ${ }^{1 *}$, ZAHID ZAHEER ${ }^{2}$ \\ ${ }^{1}$ Department of Pharmaceutics, Anuradha College of Pharmacy, Chikhli, Buldana, Maharashtra, India. ${ }^{2}$ Department of Quality Assurance, \\ Y B Chavan College of Pharmacy, Aurangabad - 431 001, Maharashtra, India. Email: nitin.gawai@gmail.com
}

Received: 27 May 2017, Revised and Accepted: 19 January 2018

\begin{abstract}
Objective: The present research study was undertaken to formulate mucoadhesive sustained release buccal tablets and patches of 5-fluorouracil (5-FU).

Method: For the research experiment work design expert software version 10 , stat-ease, Inc. has been used. A $3^{2}$ full factorial design was selected for the formulation of the buccal tablet as well as buccal patches. In this research work, formulated tablets and patches using different polymers such as carbopol 974p, polyvinylpyrrolidone-K 30, sodium deoxycholate, microcrystalline cellulose, and polyvinyl alcohol. An after formulation of batches formulated products studied for characterization, namely, Fourier transform infrared (FTIR) and differential scanning calorimeter (DSC). Evaluation parameters studied such as weight uniformity, thickness, hardness, friability, and content uniformity also carried out. For drug release purpose from the formulation of buccal tablet and patches in vitro drug released performed. In vivo drug releases study also carried out using Rabbit for drug reaction point of view.
\end{abstract}

Results: Design expert showed the significant results on independent and dependent variables. The R-Squared 0.9943 for drug release and 0.9985 for swelling index is in reasonable agreement with the formulations. FTIR and DSC indicating compatibility of the drug and polymers in the tablet formulation and patch formulations at the molecular level. The drug release of buccal tablet showed 75.10-99.34\% and buccal patches showed 58.41-81.43\%. These formulations showed good results when compared to the conventional tablet.

Conclusion: Formulation of mucoadhesive sustained release buccal tablets and patches of 5-FU successfully done using different polymers, which would definitely help in increasing bioavailability of the drug.

Keywords: Mucoadhesive sustained release, 5-Fluorouracil, Carbopol 974p, Polyvinylpyrrolidone-K 30, In vitro drug release, In vivo drug release.

(C) 2018 The Authors. Published by Innovare Academic Sciences Pvt Ltd. This is an open access article under the CC BY license (http://creativecommons. org/licenses/by/4. 0/) DOI: http://dx.doi.org/10.22159/ajpcr.2018.v11i5.20241

\section{INTRODUCTION}

Among the various routes of drug delivery, the oral route is perhaps the most preferred to the patient and the clinician alike. However, administration of drugs has disadvantages such as hepatic first pass metabolism and enzymatic degradation within the gastrointestinal (GI) tract, that prohibit oral administration of certain classes of drugs [1]. Bioadhesive drug delivery formulations were introduced in 1947 when gum tragacanth was mixed with dental adhesive powder to apply penicillin to the oral mucosa [2]. Buccal delivery of drugs provides an attractive alternate to other conventional methods of systemic drug administration since buccal mucosa is relatively permeable with rich blood supply and acts as an excellent site for the absorption of drugs. The administration of drugs through buccal route facilitate a direct entry of drug molecules into the systemic circulation, avoiding the first-pass metabolism and drug degradation in the harsh GI environment, which are often associated with oral administration. The buccal cavity is easily accessible for self-medication, and hence, it is safe and well accepted by patients since buccal patches can be very easily administered and even removed from the application site, terminating the input of drug whenever desired. Moreover, buccal patches provide more flexibility than other drug deliveries [3]. Bioadhesion can be defined as a phenomenon of interfacial molecular attractive forces in the middle of the surfaces of the biological substrate and the natural or synthetic polymers, which allows the polymer to adhere to the biological surface for an extended period [4].

The oral mucosa has many properties, which not only makes it an attractive site for drug delivery but also provides several challenges for researchers investigating novel delivery techniques to overcome many different formulations including sprays, tablets, mouthwashes, gels, pastes, and patches are presently used for delivery into and/or across the oral mucosa [5].

In recent years, delivery of therapeutic agents through mucoadhesive drug delivery system has become highly interesting. Certain drugs have the lack of efficacy due to decreased bioavailability, GI intolerance, unpredictable, and erratic absorption or presystemic elimination of other potential route for administration. The recent development in the drug delivery has intensified the investigation of mucosal drug delivery. Such route includes oral, buccal, ocular, nasal, and pulmonary routes, etc. Mucoadhesive drug delivery systems are delivery systems, which utilized the property of bioadhesion of certain polymers, which become adhesive on hydration and hence can be used for targeting a drug to a particular region of the body for an extended period. The ability to maintain a delivery system at a particular location for an extended period has great appeal for both local as well as systemic drug bioavailability. Pharmaceutical aspects of mucoadhesion have been the subject of great interest during recent years because it provides the possibility of avoiding either destruction by GI contents or hepatic firstpass inactivation of the drug [6,7].

5-Fluorouracil (5-FU) is a medication used to treat cancer. By injection into a vein, it is used for colon cancer, esophageal cancer, stomach cancer, pancreatic cancer, breast cancer, and cervical cancer. When used by injection most people develop side effects. Common side effects include inflammation of the mouth, loss of appetite, low blood 
cell counts, hair loss, and inflammation of the skin [8]. When used as a cream irritation at the site of application may occur [9]. The use of either form in pregnancy may harm the baby. FU is in the antimetabolite and pyrimidine analog families of medications $[10,11]$. How it works is not entirely clear but believed to involve blocking the action of thymidylate synthase and thus stopping the production of DNA. FU has been given systemically for anal, breast, colorectal, esophageal, stomach, pancreatic, and skin cancers (especially head-and-neck cancers). It has also been given topically (on the skin) for actinic keratoses, skin cancers, and Bowen's disease [12] and as eye drops for the treatment of ocular surface squamous neoplasia [13].

The present research study was undertaken to formulate mucoadhesive sustained release buccal tablets and patches of 5-FU using different polymer and excipients.

\section{MATERIALS AND METHODS}

\section{Materials}

5-FU, polyvinyl alcohol, talc, and sodium deoxycholate was procured from ozone international, Mumbai. Carbopol 974p, polyvinylpyrrolidone K30 was procured from Wockhardt Ltd, Aurangabad. Microcrystalline cellulose was procured from RanQ remedies Pvt. Ltd., Pune. All other ingredients were used for laboratory scale.

\section{Methods}

Formulation and preparation of mucoadhesive buccal tablets of 5-FU

The mucoadhesive buccal tablets were prepared by a direct compression method using direct compression (Cadmach, Ahmadabad). The mucoadhesive drug/polymer mixture was prepared by homogeneously mixing the carbopol 974P, polyvinylpyrrolidone (PVP) K-30, complex $(\mathrm{CP}+\mathrm{PVP})$, sodium deoxycholate, microcrystalline cellulose, and Talc. All the ingredients of the mucoadhesive buccal tablet of 5-FU were weighed (Table 1) sifted and mixed in mortar with the help of pastel. The $150 \mathrm{mg}$ mixture was then compressed using $8 \mathrm{~mm}$ punch in a single stroke on single punch tablet machine. Each tablet weighed $150 \mathrm{mg}$ [14].

\section{Experimental design}

For the research experiment work design expert software version 10, stat-ease, Inc. has been used. A $3^{2}$ full factorial design was selected because an experiment may be designed to focus attention on a single independent variable or factor. An alternative approach is to study the influence of one independent variable in conjunction with variations in one or more additional independent variables. In this research study, not only the effects of the two independent variables separately but also how they combine to influence the dependent variable. The amount of carbopol (X1) and the amount of polyvinylpyrrolidone (X2) were selected as independent variables. Two-factor $(\mathrm{X} 1, \mathrm{X} 2)$, threelevel $(-1,0,+1)$ design can be developed. Two-factor were evaluated each at three-level, and experimental trials were performed for all nine possible combinations. In vitro drug release and mucoadhesion were selected as dependent variables. The actual and coded formulation design of swellable gastro-retentive tablets according to factorial design $\left(3^{2}\right)$ layout is shown in Tables 2 and 3 [15].

\section{Formulation and preparation of mucoadhesive buccal patches of} 5-FU

The calculated amount of polymer was dissolved in distilled water with magnetic stirring for $24 \mathrm{~h}$, and then, the drug (5-FU) was incorporated into the polymeric solution with continuous stirring. The desired quantity of the plasticizer (propylene glycol) was added and kept aside for $1 \mathrm{~h}$ at room temperature. The mixture of the polymeric solution and drug of all formulas was poured on aluminum foil in a glass petri dish having $15 \mathrm{~cm}$ diameter. The petri dishes were kept on leveled surface and covered by inverted funnel to allow controlled evaporation of solvent at room temperature until a flexible patch was formed. Dried patches were carefully removed, checked for any imperfections or air bubbles and cut into small patches. The patch was packed in aluminum foil and stored in desiccator to maintain the integrity and elasticity of the patches. The composition of buccoadhesive patches is listed in Table 4 [16].

\section{Characterization}

\section{Fourier transform infrared (FTIR)}

The FTIR (IR-Affinity 1S, Shimadzu) spectra of drug, polymers, and formulations were recorded using $\mathrm{KBr}$ pellet method. The materials were triturated in porcelain mortar pestle with dry potassium bromide in the ratio (1:100). The pellets were prepared in $\mathrm{KBr}$ press at pressure 8 tones. The pellet was scanned over the range of $4000-600 / \mathrm{cm}$ and the spectra obtained were reported [17].

\section{Differential scanning calorimeter (DSC)}

DSC was performed on drug, polymers, and formulations. The physical mixtures of drug, polymers, and formulations were prepared by triturating (1:1) in a dried mortar for 5 min and kept as it is for $24 \mathrm{~h}$. The materials were weighed, 2-7 mg and sealed in aluminum pans. The sealed aluminum pan was heated at a scanning rate of $20^{\circ} \mathrm{C} / \mathrm{min}$ over a temperature range of 90 to $300^{\circ} \mathrm{C}$. Empty aluminum pan was used as a reference. The heat flow as a function of temperature was measured for the drug, and drug-polymer mixture [18].

\section{Evaluation parameters for buccoadhesive dosage form Uniformity weight of tablet and patch}

Twenty tablets were selected at random from each batch, weighed individually, and the average weight was calculated. The batch passes the test for uniformity of weight if not more than two of the individual tablet weight deviates from the average weight by more than the $7.5 \%$ as shown in Table 5.

Each patch was weighed individually on an analytical balance (Shimadzu. AUX220, Japan) and the average weights were calculated $[19,20]$.

\section{Thickness}

The thicknesses of buccal tablets were determined using digital vernier caliper (Mitutoyo, Japan) and the average was calculated. Ten individual tablets and patches from each batch were used and the average thickness was calculated [21]

\section{Friability}

The friability of the 6 tablets was determined using Roche friabilator (Electrolab, Mumbai). This device subjects the tablets to the combined effect of abrasion sand shock in a plastic chamber revolving at $25 \mathrm{rpm}$ and dropping the tablets at a height of 6 inches in each revolution. Preweighed sample of tablets was placed in the friabilator and were subjected to 100 revolutions [22]. Tablets were de-dusted using a soft muslin cloth and reweighed. The friability (F) is given by the formula:

$\mathrm{F}=(1-\mathrm{W} 0 / \mathrm{W}) \times 100$

Where,

W0 is the weight of the tablets before the test $\mathrm{W}$ is the weight of the tablet after the test.

\section{Hardness}

Pfizer hardness tester (Monsanto Rolex) was used for the determination of the tablets hardness. For each formulation the hardness of 6 tablets was evaluated [22].

\section{Surface $\mathrm{pH}$ study}

The surface $\mathrm{pH}$ of the buccal tablet was determined in order to investigate the possibility of any side effects in vivo. As an acidic or alkaline $\mathrm{pH}$ may irritate the buccal mucosa, we sought to keep the surface $\mathrm{pH}$ as close to neutral as possible. A combined glass electrode was used for this purpose. The tablet was allowed to swell by keeping 
Table 1: Composition of 5-fluorouracil mucoadhesive buccal tablet

\begin{tabular}{|c|c|c|c|c|c|c|c|c|c|}
\hline \multirow[t]{2}{*}{ Ingredients (mg) } & \multicolumn{9}{|c|}{ Formulation batches } \\
\hline & $\mathrm{FT}_{1}$ & $\mathbf{F T}_{2}$ & $\mathrm{FT}_{3}$ & $\mathrm{FT}_{4}$ & $\mathrm{FT}_{5}$ & $\mathrm{FT}_{6}$ & $\mathbf{F T}_{7}$ & $\mathrm{FT}_{8}$ & $\mathrm{FT}_{9}$ \\
\hline 5-fluorouracil & 20 & 20 & 20 & 20 & 20 & 20 & 20 & 20 & 20 \\
\hline Carbopol & 5 & 12.5 & 5 & 5 & 12.5 & 20 & 20 & 12.5 & 20 \\
\hline Polyvinylpyrolidone & 12.5 & 20 & 20 & 5 & 12.5 & 12.5 & 5 & 5 & 20 \\
\hline Sodium deoxycholate & 3 & 3 & 3 & 3 & 3 & 3 & 3 & 3 & 3 \\
\hline Microcrystalline cellulose & 5 & 5 & 5 & 5 & 5 & 5 & 5 & 5 & 5 \\
\hline Talc & 5 & 5 & 5 & 5 & 5 & 5 & 5 & 5 & 5 \\
\hline
\end{tabular}

PVP: Polyvinylpyrrolidone

Table 2: Experimental range and levels of the independent variables

\begin{tabular}{lll}
\hline \multirow{2}{*}{$\begin{array}{l}\text { Coded } \\
\text { values }\end{array}$} & \multicolumn{2}{l}{ Actual values $(\% \mathbf{w} / \mathbf{w})$} \\
\cline { 2 - 3 } & Carbopol $\left(\mathbf{X}_{\mathbf{1}}\right)$ & Polyvinylpyrrolidone $\left(\mathbf{X}_{2}\right)$ \\
\hline-1 & 5 & 5 \\
0 & 12.5 & 12.5 \\
+1 & 20 & 20 \\
\hline
\end{tabular}

Table 3: Presentation of real values of 3 levels for the statistical design

\begin{tabular}{llll}
\hline S. No & Batch & \multicolumn{2}{c}{ Variable levels in coded form } \\
\cline { 3 - 4 } & & Carbopol $\left(\mathbf{X}_{\mathbf{1}}\right)$ & Polyvinylpyrrolidone $\left(\mathbf{X}_{\mathbf{2}}\right)$ \\
\hline 1 & FT1 & -1 & 0 \\
2 & FT2 & 0 & 1 \\
3 & FT3 & -1 & 1 \\
4 & FT4 & -1 & -1 \\
5 & FT5 & 0 & 0 \\
6 & FT6 & 1 & 0 \\
7 & FT7 & 1 & -1 \\
8 & FT8 & 0 & -1 \\
9 & FT9 & 1 & 1 \\
\hline
\end{tabular}

it in contact with $1 \mathrm{~mL}$ of phosphate buffer ( $\mathrm{pH} \mathrm{6.8)} \mathrm{for} 2 \mathrm{~h}$ at room temperature. The $\mathrm{pH}$ was identified by bringing the electrode into contact with the tablet surface and allowing the surface to equilibrate for $1 \min [23,24]$.

\section{Swelling study}

Buccal tablets and patches were weighed individually; initial weight was considered as W1 and placed separately in Petri dishes containing $10 \mathrm{~mL}$ of phosphate buffer $(\mathrm{pH}$ 6.8) solution in such a way that the side of tablet and patch, which attaches to the buccal membrane was positioned to the bottom of the petri dishes with the backing membrane being viewable from the top. Tablets and patches were soaked in such a way that they completely immersed in the buffer solution. At time intervals of $12 \mathrm{~h}$, the buccal tablets and patch were removed from the petri dishes using coverslips and excess surface water was removed carefully using the Whatman filter paper. The swollen tablets and patches were then reweighed (W2). This experiment was performed in triplicate [25]. The degree of swelling (water uptake) was calculated according to the following formula:

Degree of swelling $=\frac{\text { Final weight }- \text { Initial weight }}{\text { Initial weight }} \times 100$

\section{Drug content uniformity}

Five tablets were selected at random and were powdered in a mortar; and the amount of powder equivalent to single dose was dissolved in phosphate buffer pH 6.8 up to $10 \mathrm{ml}$ by sonication (Dolphin, Mumbai) for $15 \mathrm{~min}$ and filtered through Whatman filter $(0.45 \mu \mathrm{m})$ paper. The drug content was analyzed spectrophotometrically at $261.4 \mathrm{~nm}$ using a UV spectrophotometer (Shimadzu 1601). Each measurement was carried out in triplicate and the average drug content was calculated.

Drug content uniformity was determined by dissolving the patch in $100 \mathrm{ml}$ of phosphate buffer (pH 6.8) for $24 \mathrm{~h}$ with stirring. From the solution $5 \mathrm{ml}$ was diluted with the drug content was then determined after proper dilution of the filtered solution at $266 \mathrm{~nm}$ using a UV spectrophotometer [26].

\section{Ex vivo mucoadhesive strength and force of adhesion}

A modified balance method was used for determining the ex vivo mucoadhesion strength. Goat buccal mucosa was used as the model substrate, and phosphate buffer $\mathrm{pH} 6.8$ was used as the moistening fluid. Freshly excised goat buccal mucosa was obtained from the local slaughterhouse used within $3 \mathrm{~h}$ of slaughter. The tablet and patch were laid onto the model membrane under a manual pressure of $5 \mathrm{~min}$. Bioadhesive strength was measured in terms of weight in grams of water required to detach the tablet and patch from the goat buccal mucosa. The addition of water was stopped when tablet and patch was detached from goat buccal mucosa. The weight of water required to detach the tablet and patch, respectively, from buccal mucosa was noted as $e x$ vivo mucoadhesive strength. Mucoadhesive strength was performed in duplicate, and average mucoadhesive strength was determined [23]. From this mucoadhesive strength, the force of adhesion was calculated using the following formula.

Force of adhesion $(\mathrm{N})=\frac{\text { Mucoadhesive strength }}{100} \times 9.81$

\section{Ex vivo mucoadhesive time}

The ex vivo mucoadhesion time studies were performed after application of tablet and patch, respectively, on freshly cut goat stomach mucosa. The mucosa was fixed on a glass slide using double-sided adhesive, and one side of glass slide was fixed to thread whose another end was fixed with the arm of tablet disintegration test apparatus. A side of each tablet and patch was wetted with dissolution medium and was attached to the mucosa by applying a light force with a fingertip for $20 \mathrm{~s}$. The beaker was filled with $800 \mathrm{~mL}$ of phosphate buffer of $\mathrm{pH} 6.8$ maintained at $37 \pm 0.50^{\circ} \mathrm{C}$ were used as disintegration medium and after 2 min the slide was placed in a beaker, and the apparatus was started. Care was taken that while up and down motion of the arm tablet and patch should remain in the medium. Behavior and mucoadhesive time of tablet and patch were monitored until complete detachment occurred [21].

\section{Folding endurance}

Randomly selected three films from each batch were taken to measure the folding endurance. The films were repeatedly folded at the same place until it broke. The films folded up to 300 times manually was considered satisfactory value. The number of times of film could be folded at the same place without breaking gave the value of the folding endurance [27]. 
Table 4: Composition of preliminary batches for formulation of buccal patches

\begin{tabular}{|c|c|c|c|c|c|c|c|c|c|}
\hline Ingredients & FP-1 & FP-2 & FP-3 & FP-4 & FP-5 & FP-6 & FP-7 & FP-8 & FP-9 \\
\hline 5-fluorouracil (mg) & 200 & 200 & 200 & 200 & 200 & 200 & 200 & 200 & 200 \\
\hline Carbopol 974p (mg) & 100 & 100 & 33.5 & 66.5 & 66.5 & 33.5 & 33.5 & 100 & 66.5 \\
\hline PVP k30 (mg) & 33.5 & 100 & 66.5 & 33.5 & 100 & 33.5 & 100 & 66.5 & 66.5 \\
\hline PVA (g) & 5 & 5 & 5 & 5 & 5 & 5 & 5 & 5 & 5 \\
\hline PEG (ml) & 30 & 30 & 30 & 30 & 30 & 30 & 30 & 30 & 30 \\
\hline Ethanol (ml) & 20 & 20 & 20 & 20 & 20 & 20 & 20 & 20 & 20 \\
\hline Water (ml) & 150 & 150 & 150 & 150 & 150 & 150 & 150 & 150 & 150 \\
\hline
\end{tabular}

PVP: Polyvinylpyrrolidone, PEG: Polyethylene glycol, PVA: Polyvinyl alcohol

Table 5: Limits of percentage deviation allowed underweight variation test

\begin{tabular}{ll}
\hline Average weight of tablet & \% Deviation \\
\hline $80 \mathrm{mg}$ or less & 10 \\
$80 \mathrm{mg}<x<250 \mathrm{mg}$ & 7.5 \\
$250 \mathrm{mg}$ or more & 5 \\
\hline
\end{tabular}

\section{Tensile strength (TS) measurement}

Dried patch samples were cut into uniform strips $(2.5 \mathrm{~cm} \times 5 \mathrm{~cm})$. Two pieces of cardboard $(1 \mathrm{~cm} \times 2.5 \mathrm{~cm})$ were attached to the upper and the lower end of the patch using cyanoacrylate resin adhesive. Attaching the patch to the cardboard facilitates clamping it to the jaws of the modified device used for TS measurement, thus preventing pressure on the patches and slipping before or during application. The modified device contains a rectangular frame with two jaws made up of aluminum. One jaw is stationary in the front, and the other one is movable and can be pulled by loading weights on the pan attached with string to the movable part. The patch on the cardboard was clamped between the two jaws of the device positioned at a distance of $3 \mathrm{~cm}$. The weights were gradually added to the pan until the patch was broken. The weight necessary to break the patch was noted as breaking force, and the simultaneous distance traveled by the pointer on the graph paper indicated the elongation at break (E/B) [28]. TS and percent elongation can be obtained by following formula:

$$
\begin{aligned}
\text { Tensile strength }= & \frac{\text { Force at break }(\mathrm{N})}{\text { Initial cross sectional area }} \\
& \text { of the sample }\left(\mathrm{mm}^{2}\right)
\end{aligned}
$$$$
\text { Elongation percent }=\frac{\text { Increase in length }}{\text { Original length }} \times 100
$$

\section{Ex vivo permeation study}

Permeation study was carried out for the optimized formulation using Franz diffusion cell. The tablet and patches, respectively, were placed in the donor compartment on the sheep mucosa. The mucosal layer is on donor compartment. The receptor compartment was filled with phosphate buffer $\mathrm{pH} 6.8$. The temperature was maintained at $37 \pm 0.5^{\circ} \mathrm{C}$ and $50 \mathrm{rpm}$. The amount of 5-FU permeated through sheep mucosa was determined by withdrawing $3 \mathrm{ml}$ of aliquots from the receptor compartment using a syringe and immediately replacing the same volume of the solution [14].

\section{In vitro drug release buccal tablets}

The United States pharmacopoeia (USP) type II dissolution apparatus (Veego Scientific DA6D, Mumbai) was used to study the release of drug from buccal tablets. Tablets were supposed to release the drug from one side only; therefore, an impermeable backing membrane was placed on the other side of the tablet. The tablet was further fixed to a $2 \mathrm{~cm} \times$ $2 \mathrm{~cm}$ glass slide with a solution of cyanoacrylate adhesive. In vitro drug release studies were carried out in $900 \mathrm{ml}$ of phosphate buffer solution
$\mathrm{pH} 6.8$ for $10 \mathrm{~h}$ at $100 \mathrm{rpm}$ and $37 \pm 0.5^{\circ} \mathrm{C}$. At predetermined time intervals, $1 \mathrm{ml}$ of samples were withdrawn and replaced with $1 \mathrm{ml}$ fresh medium. The samples were filtered, diluted suitably then analyzed spectrometrically at $266 \mathrm{~nm}$ [28]. All dissolution was performed in triplicate.

\section{In vitro drug release buccal patches}

The drug release study from the patches was carried out using a USP 23 Type 2 rotating paddle dissolution test apparatus (Electrolab). A total of $250 \mathrm{ml}$ of solution $\left(\mathrm{pH} 6.8\right.$ ) at $37^{\circ} \mathrm{C} \pm 5^{\circ} \mathrm{C}$ was used as the dissolution medium with a stirring rate of $50 \mathrm{rpm}$. A patch of $2.5 \mathrm{~cm}$ diameter was fixed onto a glass disc with the help of cyanoacrylate adhesive. The disc was put at the bottom of the dissolution vessel such that the patch remained on the upper side of the disc. Samples $(5 \mathrm{ml})$ were withdrawn at a predetermined time interval of $30 \mathrm{~min}$ and replaced with an equal volume of dissolution medium. The samples were filtered through a $0.45 \mathrm{~mm}$ filter and appropriately diluted with SHS solution (pH 6.8) and assayed spectrophotometrically at $266 \mathrm{~nm}$ [28]. The experiment was performed in triplicate, and average values were reported.

\section{In vivo drug release study for tablets and films}

Six male New Zealand white rabbits $(2.6 \mathrm{~kg}$ ) were selected for the in vivo study. The dose of 5-FU was adjusted based on the rabbit weight, and the optimized formulations were cut and placed in the buccal membrane with the help of a clip and tablets placed in the buccal membrane with the adhesive layer. Dextrose solution was transfused continuously throughout the period of the study. Periodically, $1 \mathrm{ml}$ of blood sample was taken by syringe containing $1 \mathrm{ml}$ of heparin solution to prevent blood clotting. These blood samples were centrifuged at $2500 \mathrm{rpm}$ for about $30 \mathrm{~min}$. One milliliter of the supernatant was taken, and after suitable dilution analyzed at $266 \mathrm{~nm}$ spectrophotometrically by the method described under in vitro analysis $[29,30]$.

\section{Stability studies}

Stability studies were carried out on the formulation, according to the ICH guidelines. The optimized formulations were selected, and the stability studies were carried out at the accelerated condition of $40 \pm 2^{\circ} \mathrm{C}, 75 \pm 5 \% \mathrm{RH}$ conditions, stored in desiccators, the formulations were packed in amber color screw cap container and kept in above-said condition for 3 months. The formulations were analyzed periodically for their physical appearance, buccoadhesive strength, and in vitro drug release $[29,31]$.

\section{RESULT AND DISCUSSION}

Evaluation parameters for factorial batches (tablet formulation) The evaluation parameters of tablets and patches are given in Tables 6 and 7 , respectively. The friability found in tablet formulations shows a good strength of tablets to withstand abrasion during transportation and general handling.

The hardness of all tablet batches was in the range of $3.1-4.2 \mathrm{~kg} / \mathrm{cm}^{2}$. Such hardness range is enough to give mechanical strength indicating good compressibility of blends. The content uniformity of drug is found in tablet between $97.98-99.87 \%$ and $90-99 \%$ in patch formulation. 
Characterization

FTIR

The IR spectrum of pure drug, polymers and physical mixture are used to establish the characteristic behavior of the drug and in its formulations. The pure drug 5-FU Figs. 1a and 2a shows peaks at $3500 / \mathrm{cm}$ to $\mathrm{N}-\mathrm{H}$ stretching, at $3100 / \mathrm{cm}$ to C-Hstretching (aromatic), at $2800 / \mathrm{cm}$ to $\mathrm{C}-H$ stretching (aliphatic), at $1730 / \mathrm{cm}$ to $\mathrm{C}=0$ stretching, at $930 / \mathrm{cm}$ to C-Fstretching. It is evident from the spectral study, that there is no difference worth mentioning in the portions of characteristic absorption bands of various functional groups and bonds present in the drug molecule and the formulations prepared from it. The drug has not lost its characteristic properties when it is converted into its different formulations. These observations support the fact that the drug has maintained its integrity in its formulations as it retained its physical characteristics without undergoing any change in its properties. This suggests that there is no interaction of the drug with polymer and excipients used in preparation of the formulations. Hence, it can be concluded that the drug has not under gone any type of interaction with the excipients used in the formulation development. From the result, it was observed that the entire characteristic peaks of 5-FU, were present in the tablet formulation and patch formulation spectrum. Thus, indicating compatibility of the drug and polymer in the tablet formulation and patch formulation at molecular level.
$D S C$

DSC thermogram of 5-FU pure drug and polymer was studied and it was found that drug 5-FU Fig. 3a shown endothermic peak at $283.17^{\circ} \mathrm{C}$. Fig. 3b Carbopol $974 \mathrm{p}$ showed endothermic peak at $82.34^{\circ} \mathrm{C}, 142.87^{\circ} \mathrm{C}$, $204.90^{\circ} \mathrm{C}$. Fig. 3c Polyvinylpyrolidone showed endothermic peak at $96.94^{\circ} \mathrm{C}, 193.30^{\circ} \mathrm{C}, 253.71^{\circ} \mathrm{C}$ and Fig. $3 \mathrm{~d}$ complex of Carbopol+PVP showed endothermic peak at $85.05^{\circ} \mathrm{C}, 161.92^{\circ} \mathrm{C}$, and $238.66^{\circ} \mathrm{C}$. This suggests that there is no interaction of the drug with polymer and excipients used in preparation of the formulations.

Mucoadhesive strength study and in vitro retention time of 5-FU buccal tablets

Carbopol and PVP have been reported to possess good mucoadhesive properties in buccal tablet formulations. When these polymers come in contact with water forms mucilage and swells, thus are responsible for mucoadhesion by simple bonding with mucus components. Mucoadhesion strength and mucoadhesion force were found good enough results, namely, $11.42-14.56 \mathrm{~g}$ and $1.079-1.428$, respectively. Mucoadhesion time was found in the range of $7.5-11.10 \mathrm{~h}$ shown in Table 8. The results of mucoadhesion study indicate that it will definitely help to retain the tablet for longer period. The swelling of the polymers is studied by their ability to imbibe water and swell

Table 6: Evaluation parameters for factorial batches (tablet formulation)

\begin{tabular}{|c|c|c|c|c|c|}
\hline \multirow{2}{*}{$\begin{array}{l}\text { Formulation } \\
\text { batches }\end{array}$} & \multicolumn{5}{|l|}{ evaluation parameters } \\
\hline & Weight uniformity (g) & Thickness (mm) & Hardness $\left(\mathrm{kg} / \mathrm{cm}^{2}\right)$ & Friability (\%) & Content uniformity (\%) \\
\hline FT1 & $132.2 \pm 0.51$ & 1.03 & $3.3 \pm 0.13$ & 0.13 & $99.28 \pm 0.20$ \\
\hline FT3 & $138.5 \pm 0.26$ & 1.02 & $3.5 \pm 0.20$ & 0.15 & $99.58 \pm 0.10$ \\
\hline FT4 & $123.0 \pm 0.72$ & 1.01 & $3.1 \pm 0.10$ & 0.15 & $98.72 \pm 0.04$ \\
\hline FT5 & $139.2 \pm 0.35$ & 1.01 & $3.2 \pm 0.18$ & 0.12 & $99.87 \pm 0.03$ \\
\hline FT6 & $146.4 \pm 0.49$ & 2.02 & $3.1 \pm 0.16$ & 0.16 & $99.46 \pm 0.01$ \\
\hline FT7 & $138.2 \pm 0.38$ & 1.02 & $3.4 \pm 0.30$ & 0.16 & $99.32 \pm 0.16$ \\
\hline FT8 & $130.4 \pm 0.23$ & 1.02 & $4.1 \pm 0.19$ & 0.14 & $99.84 \pm 0.28$ \\
\hline FT9 & $153.1 \pm 0.42$ & 2.03 & $4.0 \pm 0.25$ & 0.12 & $97.98 \pm 0.5$ \\
\hline
\end{tabular}

Table 7: Evaluation parameters for factorial batches (patch formulation)

\begin{tabular}{|c|c|c|c|c|c|c|}
\hline \multirow{2}{*}{$\begin{array}{l}\text { Formulation } \\
\text { Batches }\end{array}$} & \multicolumn{6}{|c|}{ Evaluation parameters } \\
\hline & Surface pH & Weight Uniformity (g) \pm SD & Thickness (mm) & $\begin{array}{l}\text { Folding } \\
\text { endurance }\end{array}$ & $\begin{array}{l}\text { Content } \\
\text { uniformity (\%) }\end{array}$ & $\begin{array}{l}\text { Ex-vivo resistance } \\
\text { time in hrs }\end{array}$ \\
\hline FP1 & $6.45 \pm 0.173$ & $241 \pm 2.17$ & $0.269 \pm 0.023$ & $>290$ & $90.3 \pm 1.02$ & $3.22 \pm 0.56$ \\
\hline FP2 & $6.11 \pm 0.173$ & $245 \pm 6.42$ & $0.289 \pm 0.025$ & $>290$ & $93.0 \pm 0.67$ & $4.07 \pm 0.86$ \\
\hline FP3 & $6.08 \pm 0.173$ & $263 \pm 10.6$ & $0.205 \pm 0.015$ & $>290$ & $98.3 \pm 0.12$ & $4.28 \pm 0.46$ \\
\hline FP4 & $6.36 \pm 0.208$ & $278 \pm 4.25$ & $0.260 \pm 0.015$ & $>290$ & $90.0 \pm 0.99$ & $3.77 \pm 0.33$ \\
\hline FP5 & $5.90 \pm 0.152$ & $265 \pm 1.76$ & $0.348 \pm 0.045$ & $>290$ & $96.4 \pm 0.56$ & $3.77 \pm 0.33$ \\
\hline FP6 & $7.06 \pm 0.200$ & $212 \pm 5.78$ & $0.256 \pm 0.025$ & $>290$ & $94.6 \pm 0.98$ & $4.94 \pm 0.54$ \\
\hline FP7 & $6.52 \pm 0.155$ & $282 \pm 3.24$ & $0.370 \pm 0.010$ & $>290$ & $99.0 \pm 0.19$ & $3.55 \pm 0.99$ \\
\hline FP8 & $5.98 \pm 0.251$ & $269 \pm 2.65$ & $0.234 \pm 0.011$ & $>290$ & $97.0 \pm 0.49$ & $3.98 \pm 0.33$ \\
\hline FP9 & $7.32 \pm 0.360$ & $277 \pm 5.36$ & $0.245 \pm 0.028$ & $>290$ & $96.3 \pm 0.85$ & $4.57 \pm 0.33$ \\
\hline
\end{tabular}

*SD: Standard deviation, $\mathrm{n}=10, \mathrm{n}=3, \mathrm{n}=3$

Table 8: Mucoadhesive strength study and in vitro retention time of 5-FU buccal tablets

\begin{tabular}{|c|c|c|c|c|}
\hline Formulation batches & Mucoadhesive strength (gm) & Mucoadhesive force (N) & In vitro retention time & Swelling index (\%) \\
\hline FT1 & $11.42 \pm 0.10$ & 1.120 & $8 \mathrm{~h} 42 \mathrm{~min}$ & 48.16 \\
\hline FT2 & $12.86 \pm 0.12$ & 1.261 & 9 h $40 \mathrm{~min}$ & 53.24 \\
\hline FT3 & $11.00 \pm 0.08$ & 1.079 & $7 \mathrm{~h} 50 \mathrm{~min}$ & 41.23 \\
\hline FT4 & $11.69 \pm 0.61$ & 1.146 & $9 \mathrm{~h} 01 \mathrm{~min}$ & 38.46 \\
\hline FT5 & $12.82 \pm 0.50$ & 1.257 & 9 h 35 min & 43.19 \\
\hline FT6 & $13.94 \pm 0.31$ & 1.367 & $10 \mathrm{~h} 15 \mathrm{~min}$ & 58.32 \\
\hline FT7 & $13.19 \pm 0.31$ & 1.293 & 9 h 55 min & 49.17 \\
\hline FT9 & $14.56 \pm 0.31$ & 1.428 & $11 \mathrm{~h} 10 \mathrm{~min}$ & 62.12 \\
\hline
\end{tabular}

5-FU: 5-fluorouracil 
enormously. In the present study, polymers used in the formulation carbopol and PVP have been reported to show good swelling properties. These polymers in combination showed good swelling properties ranging from $38.46 \%$ to $62.12 \%$ as shown in Table 8 and Fig 4 . This increase in swelling was possible only due to imbibitions and mucilage formation of polymers when it comes in contact with biological and or aqueous medium and due to which swelling took place.

\section{Mucoadhesive strength of buccal patch formulation}

\section{Mucoadhesive strength}

From the mucoadhesive strength data, it was found that the drug release study the patch prepared carbopol in the amount of $100 \mathrm{mg}$ (FP1), $200 \mathrm{mg}$ (FP2), and $400 \mathrm{mg}$ (FP3) were about 8.70 $\pm 0.17,9.10 \pm 0.14$, and $9.56 \pm 0.24$, respectively. Patch containing PVP in the amount of $100 \mathrm{mg}$ (FP4), $1200 \mathrm{mg}$ (FP5), and $400 \mathrm{mg}$ (FP6) were about 9.23 \pm 0.09 , $14.5 \pm 0.70$, and $10.6 \pm 0.12$, respectively.

The patch prepared with carbopol and PVP with the amount of $50 \mathrm{mg}$ (FP7) shows maximum mucoadhesive strength of $18.5 \pm 0.23$. The patch prepared with carbopol and PVP with the amount of $100 \mathrm{mg}$ (FP8) shows mucoadhesive strength of $14.5 \pm 0.23$. The patch prepared with carbopol and PVP with the amount of $100 \mathrm{mg}$ (FP9) shoes mucoadhesive strength of $13.01 \pm 0.23$ as shown in Table 9 and Fig. 5 [32].

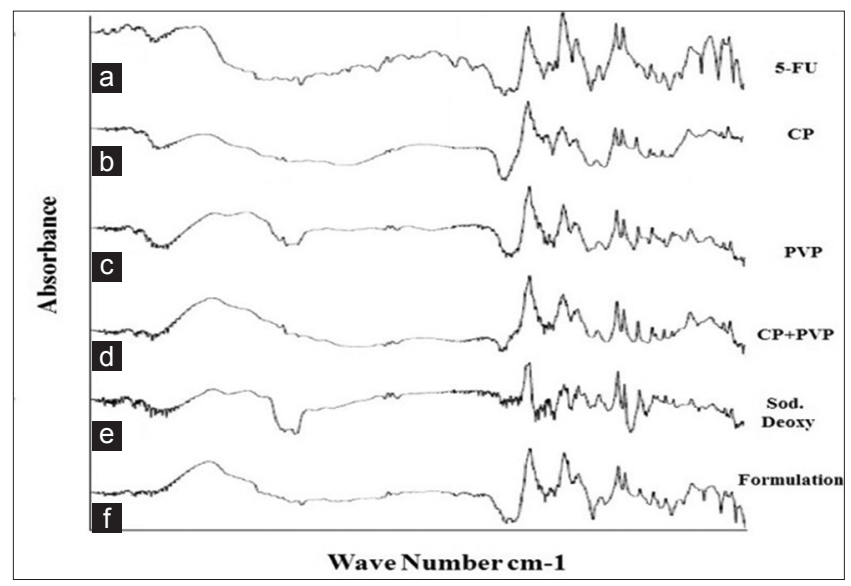

Fig. 1: Fourier transform infrared, (a) 5-fluorouracil, (b) CP, (c) polyvinylpyrrolidone (PVP), (d) complex CP+PVP, (e) sodium deoxycholate, (f) tablet formulation

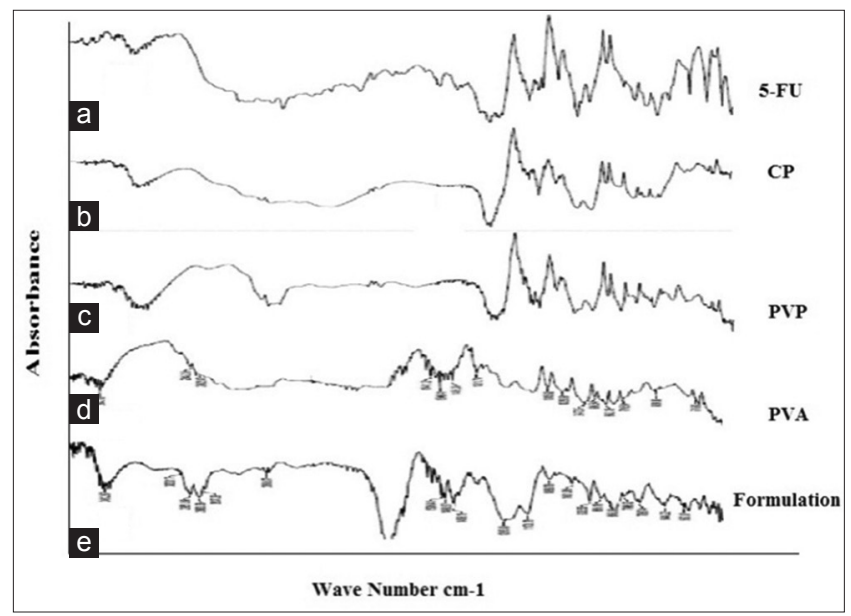

Fig. 2: Fourier transform infrared, (a) 5-fluorouracil, (b) CP, (c) polyvinylpyrrolidone, (d) polyvinyl alcohol, (e) patch formulation

\section{Surface $p H$ of patch}

Surface $\mathrm{pH}$ was determined by the patch were allowed in contact with $1 \mathrm{ml}$ of distilled water. The surface $\mathrm{pH}$ was noted by bringing a combined glass electrode or $\mathrm{pH}$ paper near the surface of patch and allowing equilibrate for $1 \mathrm{~min}$ and the average surface $\mathrm{pH}$ of all patches are given in Table 10. From the surface $\mathrm{pH}$ data, it was found that patch prepared carbopol in amount of $100 \mathrm{mg}$ (F1), $200 \mathrm{mg}$ (F2), $400 \mathrm{mg}$ (F3) were about $6.45 \pm 0.173,6.11 \pm 0.173$, and $6.08 \pm 0.173$, respectively. Patch containing PVP in the amount of $100 \mathrm{mg}$ (F4), $200 \mathrm{mg}$ (F5), and $400 \mathrm{mg}$ (F6) were about $6.36 \pm 0.208,5.90 \pm 0.152$, and $7.06 \pm 0.200$. The patch prepared with carbopol and PVP with the amount of $100 \mathrm{mg}$ (F7), $120 \mathrm{mg}$ (F8), and $80 \mathrm{mg}$ (F9) were about $6.52 \pm 0.155,5.98 \pm 0.251$, and $7.32 \pm 0.360$ [33].

\section{Drug content uniformity of patch}

In each case, three patches were used and the average drug content was calculated. From the in folding endurance data, it was found that patch prepared carbopol in amount of $100 \mathrm{mg}$ (F1), $200 \mathrm{mg}$ (F2), and $400 \mathrm{mg}$ (F3) were about $90.3 \pm 1.02,93.0 \pm 0.67$, and $98.3 \pm 0.12$, respectively. Patch containing PVP in the amount of $100 \mathrm{mg}$ (F4), $200 \mathrm{mg}$ (F5), and $400 \mathrm{mg}$ (F6) were about $90.0 \pm 0.99,96.4 \pm 0.56$, and $94.6 \pm 0.98$, respectively. The patch prepared with carbopol and PVP with the amount of $100 \mathrm{mg}$ (F7), $120 \mathrm{mg}$ (F8), and $80 \mathrm{mg}$ (F9) were about 99.0 $\pm 0.19,97.0 \pm 0.49$, and $96.3 \pm 0.85$ shown in Table 10 [34].

\section{Folding endurance of patch}

The folding endurance of the patch was determined by repeatedly folding a small strip of the patch at the same place until it broke and the average folding endurance of all patch is given in Table 10. From the in folding endurance data, it was found that patch prepared carbopol in amount of $100 \mathrm{mg}$ (F1), $200 \mathrm{mg}$ (F2), and $400 \mathrm{mg}$ (F3) were about $>290,>290,>290$. Patch containing PVP in amount of $100 \mathrm{mg}$ (F4),

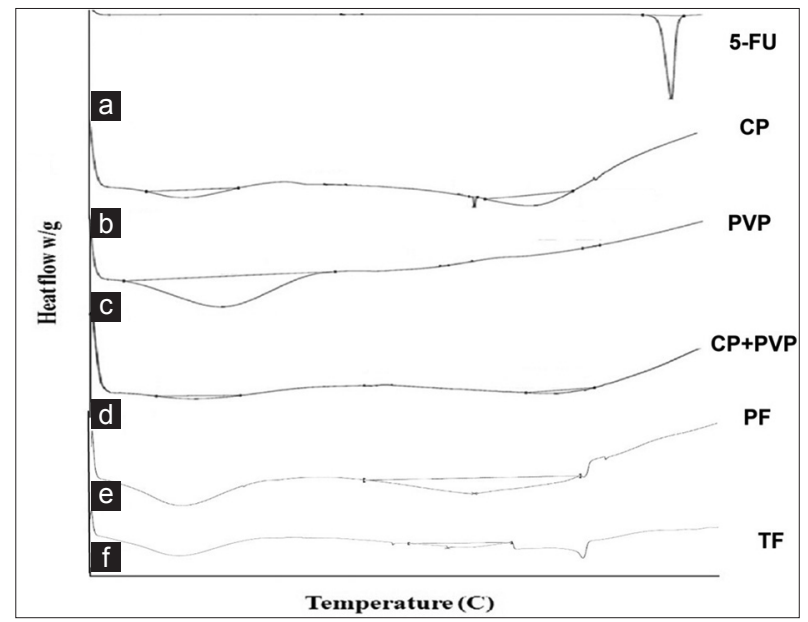

Fig. 3: Differential scanning calorimeter (a) 5-fluorouracil, (b) $\mathrm{CP}$ (c) polyvinylpyrrolidone, (d) complex CP+PVP, (e) buccalpatches formulation (PF), (f) buccaltablet formulation (TF)

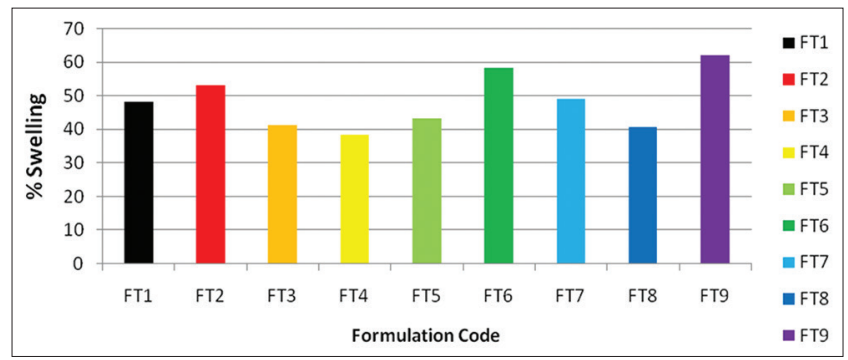

Fig. 4: Swelling index of tablet formulation 
$200 \mathrm{mg}$ (F5), and $400 \mathrm{mg}$ (F6) were about >290, >290, >290. The patch prepared with carbopol and PVP with amount of $100 \mathrm{mg}$ (F7), $120 \mathrm{mg}$ (F8), 80 mg (F9) were about >290, >290, >290 [34].

\section{Thickness of patch}

The thickness of the patch was measured using vernier caliper and the average thickness of all patches is shown in Table 10. Thickness of film prepared of carbopol in amount of $100 \mathrm{mg}$ (F1), $2000 \mathrm{mg}$ (F2), $400 \mathrm{mg}$ (F3) were found to $0.269 \pm 0.023,0.289 \pm 0.025,0.205 \pm 0.015$. Patch containing PVP in amount of $100 \mathrm{mg}$ (F4), $200 \mathrm{mg}$ (F5), and $400 \mathrm{mg}$ (F6) were found to be $0.260 \pm 0.015,0.348 \pm 0.045,0.256 \pm 0.025$, respectively. The patch prepared with carbopol and PVP with amount of $100 \mathrm{mg}$ (F7), $120 \mathrm{mg}$ (F8), and $80 \mathrm{mg}$ (F9) were about $0.370 \pm 0.010$, $0.234 \pm 0.011,0.245 \pm 0.028[34]$.

\section{Weight uniformity of patch}

The weight of prepared patch was determined using digital balance and the average weights of all patches are given in Table 10. Patch prepared carbopol in amount of $100 \mathrm{mg}$ (F1), $200 \mathrm{mg}$ (F2), $400 \mathrm{mg}$ (F3) were about $241 \pm 2.17,245 \pm 6.42,263 \pm 10.6$, respectively. Patch containing PVP in amount of $100 \mathrm{mg}$ (F4), $200 \mathrm{mg}$ (F5), and $400 \mathrm{mg}$ (F6) were about $278 \pm 4.25,265 \pm 1.76,212 \pm 5.78$, respectively. The patch prepared with carbopol and PVP with amount of $100 \mathrm{mg}$ (F7), $120 \mathrm{mg}$ (F8), and $80 \mathrm{mg}$ (F9) were about 282 $\pm 3.24,269 \pm 2.65$, $277 \pm 5.36[33]$.

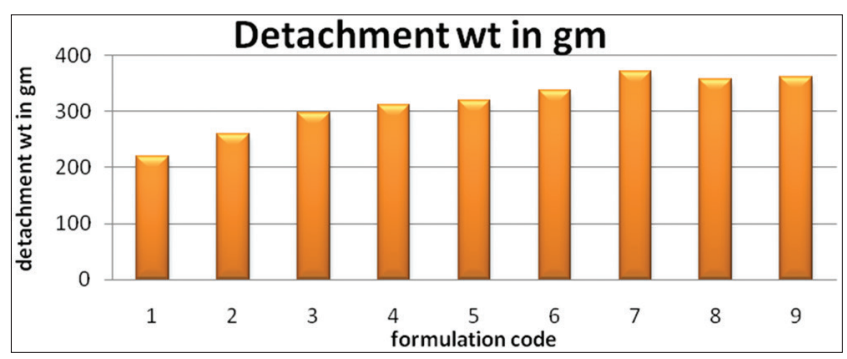

Fig. 5: Mucoadhesive strength of buccal patches

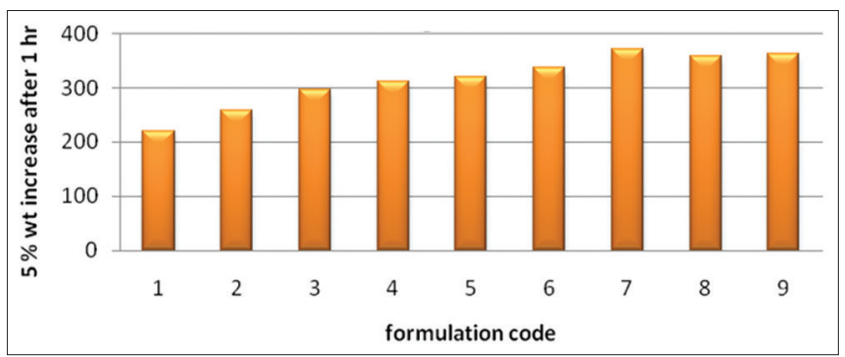

Fig. 6: Swelling index after $1 \mathrm{~h}$

\section{Swelling index}

From the swelling index data, it was found that, the drug release study the patch prepared carbopol in the amount of $100 \mathrm{mg}$ (F1), $200 \mathrm{mg}$ (F2), $400 \mathrm{mg}$ (F3) were $16.12 \pm 1.32,16.76 \pm 0.95$, and $17.40 \pm 1.10$, respectively. Patch containing PVP in amount of $100 \mathrm{mg}$ (F4), $1200 \mathrm{mg}$ (F5), and $400 \mathrm{mg}$ (F6) were about 18.12 $\pm 0.76,18.95 \pm 0.89$, and 20.05 \pm 2.52 , respectively. The patch prepared with carbopol and PVP with amount of $50 \mathrm{mg}$ (F7) shows maximum swelling index of $25.12 \pm 1.26$. The film prepared with carbopol and PVP with amount of $100 \mathrm{mg}$ (F8) shows swelling index of $23.51 \pm 3.06$. The film prepared with carbopol and PVP with amount of $100 \mathrm{mg}$ (F9) shows swelling index of $24.01 \pm 4.80$ shown in Table 11 and Fig 6 [32].

\section{TS}

From the TS data, it was found that the drug release study the patch prepared carbopol in amount of $100 \mathrm{mg}$ (F1), $200 \mathrm{mg}$ (F2), and $400 \mathrm{mg}$ (F3) were 220.15, 259.32, and 297.57, respectively. Patch containing PVP in amount of $100 \mathrm{mg}$ (F4), $1200 \mathrm{mg}$ (F5), and $400 \mathrm{mg}$ (F6) were about $312.45,320.54$, and 337.56, respectively. The patch prepared with carbopol and PVP with the amount of $50 \mathrm{mg}$ (F7) shows maximum TS of 371.81. The film prepared with carbopol and PVP with amount of $100 \mathrm{mg}$ (F8) shows TS of 358.66. The patch prepared with carbopol and PVP with amount of $100 \mathrm{mg}$ (F9) shows TS of 361.95 shown in Table 11 and Fig 7 [32].

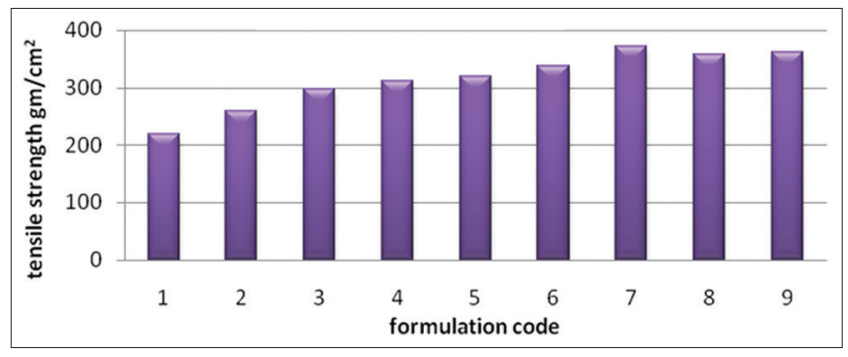

Fig. 7: Tensile strength $\mathrm{g} / \mathrm{cm}^{2}$

Table 9: Mucoadhesive strength of formulation

\begin{tabular}{ll}
\hline Formulation code & Detachment weight in $\mathbf{~}$ \\
\hline FP1 & $8.70 \pm 0.17$ \\
FP2 & $9.10 \pm 0.14$ \\
FP3 & $9.56 \pm 0.24$ \\
FP4 & $9.23 \pm 0.09$ \\
FP5 & $14.5 \pm 0.70$ \\
FP6 & $10.6 \pm 0.12$ \\
FP7 & $18.5 \pm 0.23$ \\
FP8 & $14.5 \pm 0.23$ \\
FP9 & $13.01 \pm 0.23$ \\
\hline
\end{tabular}

Table 10: Mucoadhesive strength study and in vitro retention time of 5-FU buccal patches

\begin{tabular}{|c|c|c|c|c|c|c|}
\hline \multirow{2}{*}{$\begin{array}{l}\text { Formulation } \\
\text { batches }\end{array}$} & \multicolumn{6}{|c|}{ Evaluation parameters } \\
\hline & Surface $\mathrm{pH}$ & Weight uniformity (g) \pm SD & Thickness (mm) & $\begin{array}{l}\text { Folding } \\
\text { endurance }\end{array}$ & $\begin{array}{l}\text { Content } \\
\text { uniformity (\%) }\end{array}$ & $\begin{array}{l}\text { Ex-vivo resistance } \\
\text { time in hrs }\end{array}$ \\
\hline FP1 & $6.45 \pm 0.173$ & $241 \pm 2.17$ & $0.269 \pm 0.023$ & $>290$ & $90.3 \pm 1.02$ & $3.22 \pm 0.56$ \\
\hline FP2 & $6.11 \pm 0.173$ & $245 \pm 6.42$ & $0.289 \pm 0.025$ & $>290$ & $93.0 \pm 0.67$ & $4.07 \pm 0.86$ \\
\hline FP3 & $6.08 \pm 0.173$ & $263 \pm 10.6$ & $0.205 \pm 0.015$ & $>290$ & $98.3 \pm 0.12$ & $4.28 \pm 0.46$ \\
\hline FP4 & $6.36 \pm 0.208$ & $278 \pm 4.25$ & $0.260 \pm 0.015$ & $>290$ & $90.0 \pm 0.99$ & $3.77 \pm 0.33$ \\
\hline FP6 & $7.06 \pm 0.200$ & $212 \pm 5.78$ & $0.256 \pm 0.025$ & $>290$ & $94.6 \pm 0.98$ & $4.94 \pm 0.54$ \\
\hline FP7 & $6.52 \pm 0.155$ & $282 \pm 3.24$ & $0.370 \pm 0.010$ & $>290$ & $99.0 \pm 0.19$ & $3.55 \pm 0.99$ \\
\hline FP8 & $5.98 \pm 0.251$ & $269 \pm 2.65$ & $0.234 \pm 0.011$ & $>290$ & $97.0 \pm 0.49$ & $3.98 \pm 0.33$ \\
\hline FP9 & $7.32 \pm 0.360$ & $277 \pm 5.36$ & $0.245 \pm 0.028$ & $>290$ & $96.3 \pm 0.85$ & $4.57 \pm 0.33$ \\
\hline
\end{tabular}




\section{In vitro study of buccal tablet}

$\mathrm{A} 3^{2}$ full factorial design was constructed to study the effect of the amount of carbopol 974p (X1) and PVP (X2) on drug release from tablets. The dependent variables chosen were drug release and mucoadhesion. In drug release study of 5-FU was found to be a function of the polymer concentration. It was observed that the variation in concentration of polymer from factorial batches FT1 to FT9 have variability on release rate of drug. The influence of carbopol 974p and PVP ratio on the release of 5-FU from the tablets in phosphate buffer having $\mathrm{pH} 6.8$ at $37 \pm 0.5^{\circ} \mathrm{C}$. It is clear that increase in concentration of carbopol $974 \mathrm{p}$ and PVP in formulae decreased the release rate. The formulation FT-5 showed the best $99.34 \%$ drug release.

Formulations FT-6, FT-7, and FT-9 containing higher concentrations of carbopol $974 \mathrm{p}$ showed less drug release from $79.61 \%$ to $85.42 \%$ as compared to other formulation batches, out of which batch FT-9 showed very less drug release due to higher concentrations of carbopol 974p and PVP. The formulations FT-1, FT-2 and FT-3 showed increase in drug release from $80.76 \%$ to $92.46 \%$ due to decrease in concentration of carbopol 974p and PVP. The Formulations FT-4, FT-5, and FT-8 showed drug release from $75.10 \%$ to $99.34 \%$, in which the polymer concentration was found optimum in batch F-3 which showed drug release up to $99.34 \%$. The batch FT-4 showed less drug release. Cumulative drug release buccal tablet shown in Fig. 8.

\section{Final equation in terms of coded factors}

$\%$ Drug release $=+97.48-6.06 * A-2.16 * B-6.82 * A B-10.52 * A^{2}-13.46^{*} B^{2}$

\section{In vitro study of buccal patch}

From the in vitro dissolution data, it was found that the drug release study the patch prepared Carbopol in amount of $100 \mathrm{mg}$ (FP1), $200 \mathrm{mg}$ (FP2), $400 \mathrm{mg}$ (FP3) were about $73.07 \pm 0.72 \%, 60.06 \pm 0.68 \%, 76.61 \pm 0.32 \%$ drug release, respectively. Patch containing PVP in amount of $100 \mathrm{mg}$ (FP4), $200 \mathrm{mg}$ (FP5), and $400 \mathrm{mg}$ (FP6) were about 59.54 $\pm 0.55 \%$, $58.41 \pm 0.52 \%, 54.27 \pm 0.51 \%$ drug relSease, respectively. The patch

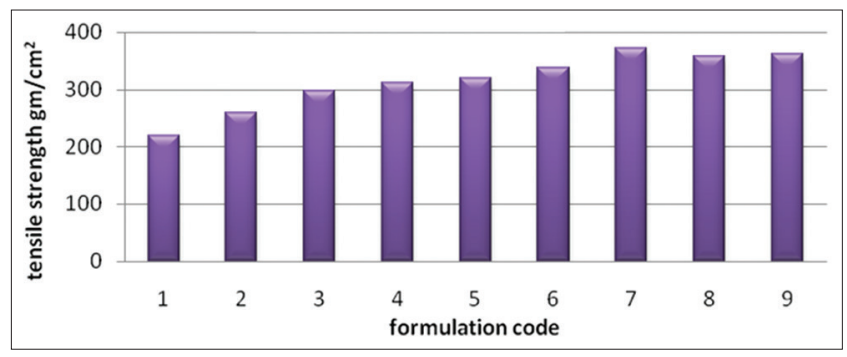

Fig. 7: Tensile strength $\mathrm{g} / \mathrm{cm}^{2}$

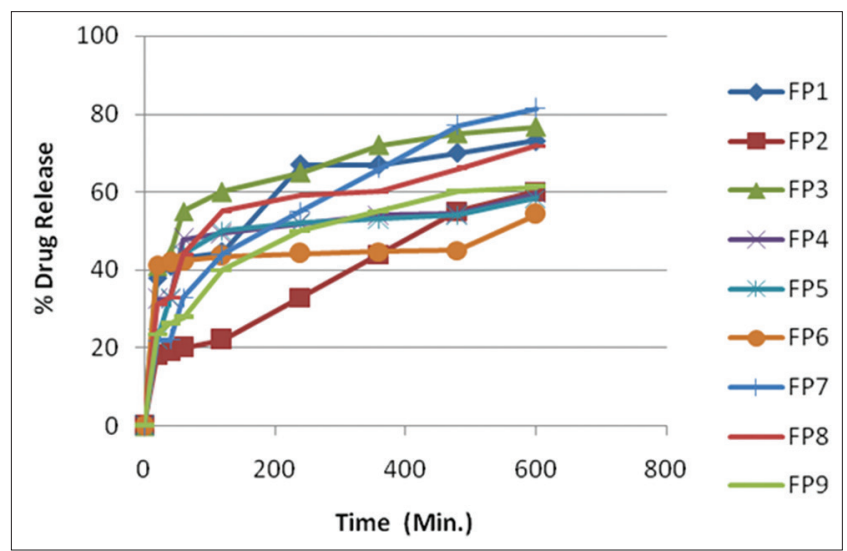

Fig. 8: Cumulative drug release buccal tablet prepared with carbopol and PVP with Amount of $100 \mathrm{mg}$ (FP7) shows maximum dissolution of $81.43 \pm 0.54$. The patch prepared with carbopol in amount of $100 \mathrm{mg}$ with PVA in $50 \mathrm{mg}$ (FP8) shows dissolution of $71.84 \pm 0.69 \%$. The patch prepared with carbopol in amount of $50 \mathrm{mg}$ with PVA in $100 \mathrm{mg}$ (FP9) shows dissolution of $67.17 \pm 0.74 \%$. From the above results, it can be concluded that increasing concentration of polymer that is carbopol and PVP increases drug release. Combined effect of carbopol and PVP in (1:1) shown much better drug release profile. Cumulative \% drug release of buccal patches shown in Fig. $9[16,35]$.

\section{Ex vivo permeation studies}

5-FU permeation from formulations FT-5 across sheep mucosa over $10 \mathrm{~h}$ is shown in Fig 10. The maximum permeation of 5-FU from FT-5 and FP-5 was $96 \%$ and $69 \%$ at $10 \mathrm{~h}$ and $8 \mathrm{hrs}$, respectively. Regression of the linear portions of the two plots gave slopes and intercepts from which the permeation flux (slope divided by mucosal surface area) of FT-5 and FP-5 were calculated to be 8.366 and $5.233 \mathrm{mg} / \mathrm{cm} 2 / \mathrm{h}$, respectively. While permeation coefficients were found be 2.36 and $1.43 \mathrm{~cm} / \mathrm{h}$ for FT-5 and FP-5 formulations, respectively. In formulation FT-5 and FP- 5 addition of sodium deoxycholate and polyethylene glycol increased the cumulative percentage of drug permeated. This may be due to sodium deoxycholate and Polyethylene glycol extracted only mucosal lipid from the intercellular spaces. Thus, this enhances the diffusivity of the 5-FU through the par cellular or polar route, along with the extraction of mucosal lipid from the intercellular spaces by the formation of micelles. This resulted in enhancing passive diffusivity of the 5-FU throughtranscellular (crossing the cell membranes and entering the cell) and par cellular routes.

\section{ANOVA analysis for drug release and mucoadhesion}

Evaluation and interpretation of research findings are important and the $p$-value serves a valuable purpose in these findings. ANOVA for the dependent variables drug release and Mucoadhesion was done. The coefficients of X1 and X2 were found to be significant at $\mathrm{p}<0.05$, hence confirmed that both the variables have significant effect on the selected responses. Overall, both the variables caused significant change in the responses. ANOVA and response surface analysis were performed using design expert software.

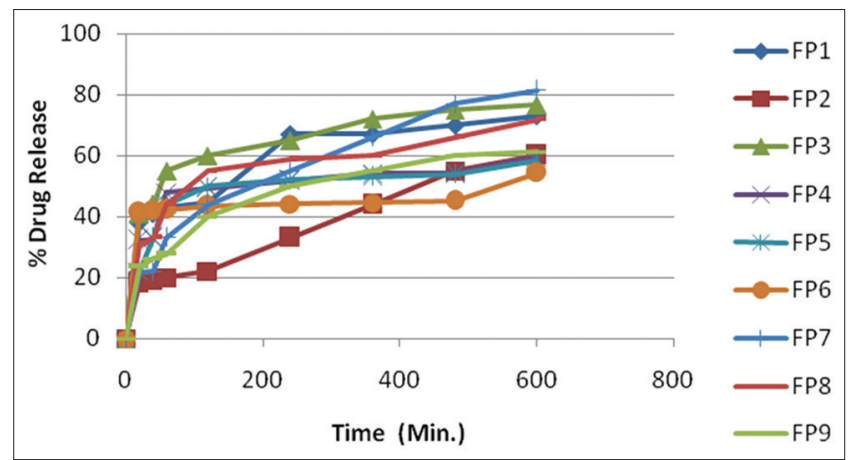

Fig. 9: Cumulative $\%$ drug release of buccal patches

Table 11: Swelling index and tensile strength

\begin{tabular}{lll}
\hline Formulation code & $\begin{array}{l}\text { Swelling index (\% wt } \\
\text { increase after } \mathbf{1} \text { h) }\end{array}$ & $\begin{array}{l}\text { Tensile } \\
\text { strength } \mathbf{( g / c m})\end{array}$ \\
\hline FP1 & $16.12 \pm 1.32$ & 220.15 \\
FP2 & $16.76 \pm 0.95$ & 259.32 \\
FP3 & $17.40 \pm 1.10$ & 297.57 \\
FP4 & $18.12 \pm 0.76$ & 312.45 \\
FP5 & $18.95 \pm 0.89$ & 320.54 \\
FP6 & $20.05 \pm 2.52$ & 337.56 \\
FP7 & $25.12 \pm 1.26$ & 371.81 \\
FP8 & $23.51 \pm 3.06$ & 358.66 \\
FP9 & $24.01 \pm 4.80$ & 361.95 \\
\hline
\end{tabular}




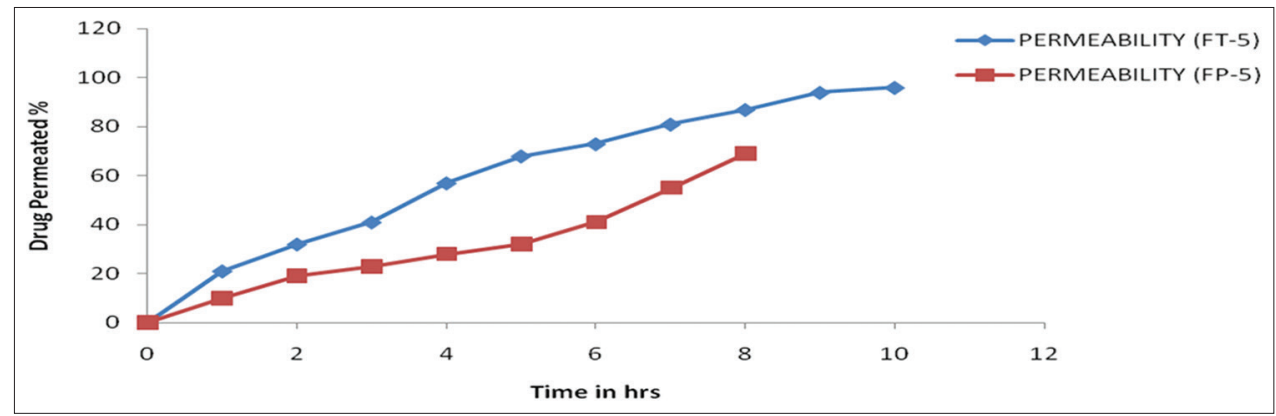

Fig. 10: Ex vivo permeation studies of FT-5 and FP-5 formulation

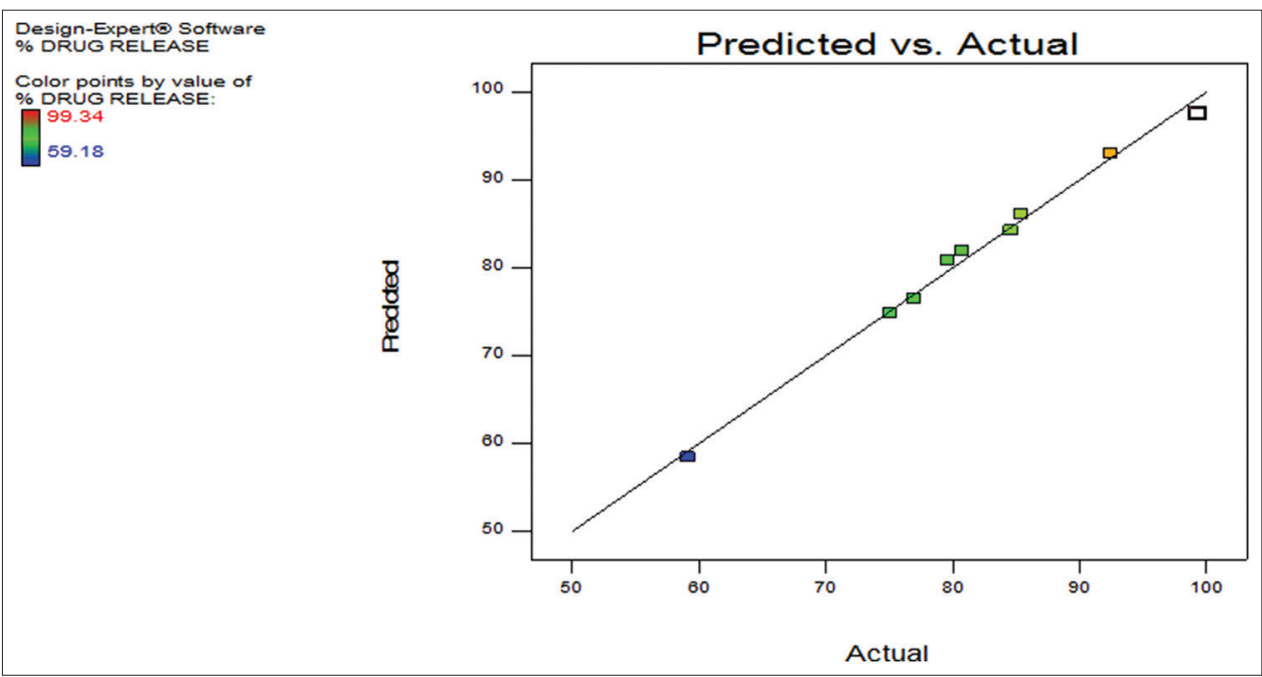

Fig. 11: Predicted versus actual plot of $\%$ drug release for tablet formulation

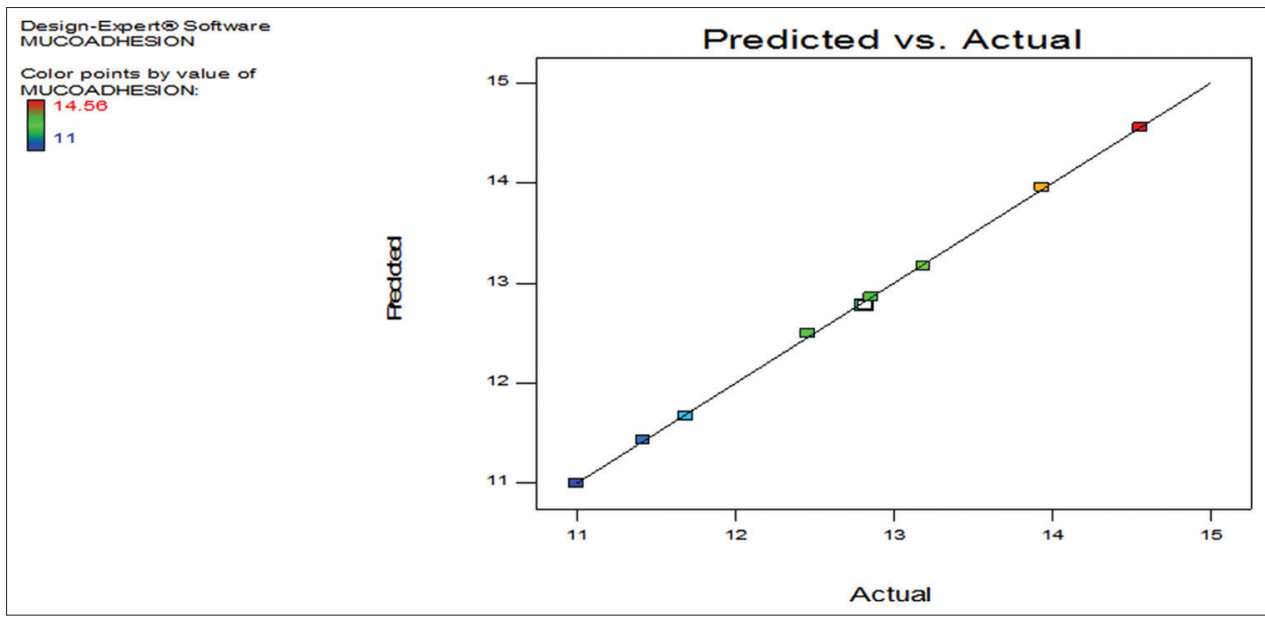

Fig. 12: Predicted versus actual plot of mucoadhesion for tablet formulation

Table 12: Analysis of variance table (Partial sum of squares - Type III)

\begin{tabular}{llllll}
\hline Source & Sum of source & Df & Mean squares & F value & p-value Probe>F \\
\hline Model & 1018.76 & 5 & 203.75 & 74.24 & 0.0024 \\
A-Carbopol & 220.58 & 1 & 220.58 & 80.37 & 0.0029 \\
B-Polyvinylpyrilidone & 28.04 & 1 & 28.04 & 10.22 & 0.0495 \\
AB & 186.19 & 1 & 186.19 & 67.84 & 0.0037 \\
A $^{2}$ & 221.34 & 1 & 221.34 & 80.65 & 0.0029 \\
B $^{2}$ & 362.61 & 1 & 362.61 & 132.12 & 0.0014 \\
Residual & 8.23 & 3 & 2.74 & & Significant \\
Core Total & 1026.99 & 8 & & & Significant \\
\end{tabular}




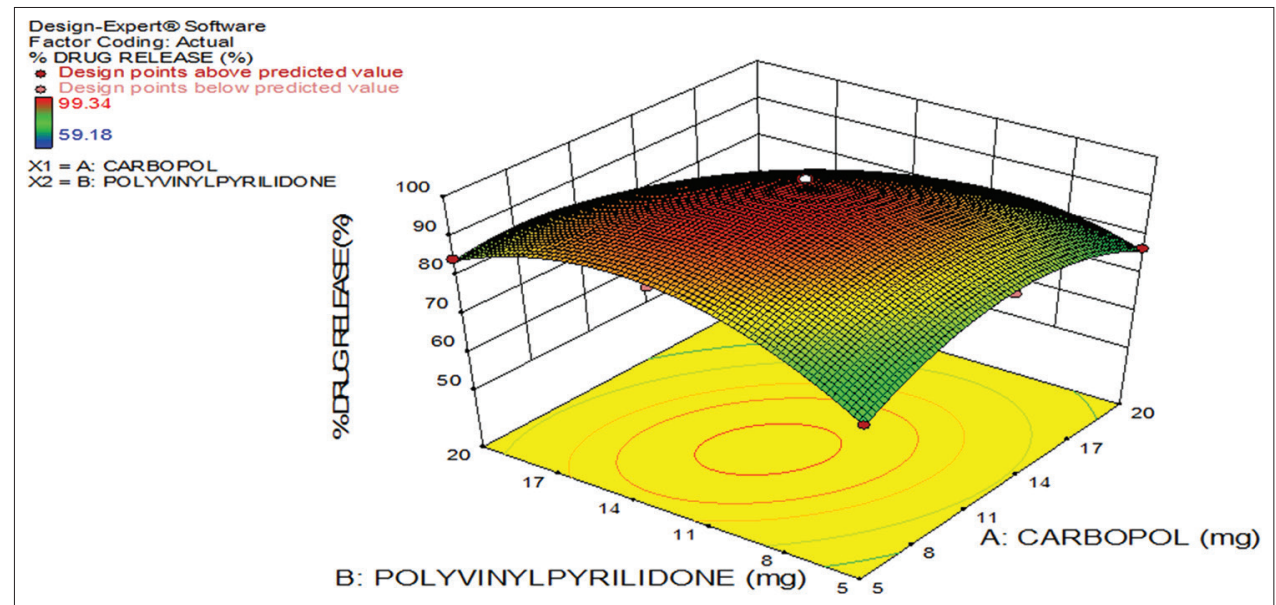

Fig. 13: 3D graph of $\%$ drug release for tablet formulation

Table 13: Standard deviation, mean and $\mathbf{R}^{2}$ for dissolution

\begin{tabular}{lllll}
\hline Std.Dev & 1.66 & 0.75 & $\mathrm{R}^{2}$ & 0.9920 \\
Mean & 81.49 & 92.30 & Adj R-Squared & 0.9786 \\
C.V.\% & 2.03 & 0.82 & Pred R-Squared & 0.9382 \\
PRESS & 63.52 & 13.96 & Adeq Precision & 28.856 \\
\hline
\end{tabular}

Table 14: Analysis of variance table (Partial sum of squares - Type III)

\begin{tabular}{lllllll}
\hline Source & Sum of source & Df & Mean squares & F value & p-value Probe>F & Observation \\
\hline Model & 10.86 & 5 & 2.17 & 1348.66 & $<0.0001$ & Significant \\
A-Carbopol & 9.58 & 1 & 9.58 & 5943.77 & $<0.0001$ & Significant \\
B-Polyvinylpyrilidone & 0.19 & 1 & 0.19 & 120.66 & 0.0016 & Significant \\
AB & 1.06 & 1 & 1.06 & 658.49 & 0.0001 & Significant \\
$\mathrm{A}^{2}$ & 0.013 & 1 & 0.013 & 7.94 & 0.0668 & Significant \\
$\mathrm{B}^{2}$ & 0.020 & 1 & 0.020 & 12.41 & 0.0388 & Significant \\
Residual & $4.833 \mathrm{E}-003$ & 3 & $1.611 \mathrm{E}-003$ & & & \\
Core total & 10.87 & 8 & & & & \\
\hline
\end{tabular}

\section{Response surface analysis}

The quadratic model obtained from the regression analysis was used to build a 3-D graphs in which the responses were represented by curvature surface as a function of independent variables. The relationship between the response and independent variables can be directly visualized from the response surface plots presented in Figs. 11-14. Predicted plots (Figs. 11 and 12) are representations of the responses for the selected factors and shows that the predicted results and practically obtained results are similar. Three dimensional (3-D) surface plots (Figs. 13 and 14) for the obtained responses were drawn based on the model polynomial functions to assess the change of the response surface and also indicates that increase in concentration of carbopol decreases the $\%$ drug release. These plots explain the relationship between the dependent and independent variables, i.e., the effects of two factors on the response at one time. The response surface analysis for drug release and mucoadhesion was studied which showed significant results. The Model F-value of 74.24 and 1348.66 for drug release and mucoadhesion implies the model is significant. Values of $\mathrm{p}<0.0500$ indicate model terms are significant. The results are shown in Tables 12-15.

\section{Final equation in terms of actual factors}

\% Drug Release $=+25.61528+5.38322 *$ Carbopol $+7.21233^{*}$ Polyvinylpyrilidone-0.12129* Carbopol* Polyvinylpyrilidone-0.18702* Carbopol $^{2}-0.23938^{*}$ Polyvinylpyrilidone ${ }^{2}$

\section{Final equation in terms of coded factors}

Mucoadhesion $=+12.78+1.26 * \mathrm{~A}+0.18 * \mathrm{~B}+0.52 * \mathrm{AB}-0.080^{*} \mathrm{~A}^{2}-0.100^{*} \mathrm{~B}^{2}$
Table 15: Standard deviation, mean and $\mathbf{R}^{2}$ for mucoadhesion

\begin{tabular}{lllll}
\hline Std.Dev & 0.040 & 0.75 & R-Squared & 0.9996 \\
Mean & 12.66 & 92.30 & Adj R-Squared & 0.9988 \\
C.V. \% & 0.32 & 0.82 & Pred R-Squared & 0.9962 \\
Press & 0.042 & 13.96 & Adeq Precision & 108.524 \\
\hline
\end{tabular}

Table 16: Summary of mean pharmacokinetic parameters for buccal patch, buccal tablet and reference (conventional tablet) in healthy rabbits

\begin{tabular}{lllll}
\hline SN & $\begin{array}{l}\text { Pharmacokinetic } \\
\text { parameters }\end{array}$ & $\begin{array}{l}\text { Buccal } \\
\text { patch }\end{array}$ & $\begin{array}{l}\text { Buccal } \\
\text { tablet }\end{array}$ & $\begin{array}{l}\text { Conventional } \\
\text { tablet }\end{array}$ \\
\hline 1 & Cmax $(\mathrm{ng} / \mathrm{ml})$ & 215 & 231 & 227 \\
2 & $\mathrm{~T} \max (\mathrm{h})$ & 3 & 8 & 4 \\
3 & $\mathrm{AUC}_{0-\infty}(\mathrm{ng} \cdot \mathrm{h} / \mathrm{ml})$ & 2534 & 2754 & 1603 \\
4 & Slope & -3.865 & -4.119 & -0.351 \\
\hline
\end{tabular}

Final equation in terms of actual factors

Mucoadhesion $=+11.30500+0.089556^{*} \mathrm{C}$ arbo pol $-0.046000 *$ Polyvinylpyrilidone+9.15556E-003* CARBOPOL* Polyvinylpyrilidone1.42222E-003* Carbopol$^{2}-1.77778 \mathrm{E}-003 *$ Polyvinylpyrilidone ${ }^{2}$

From the equation for dissolution, the information conveyed was: $\mathrm{R}^{2}$ was high indicating the adequate fitting of the quadratic model. As carbopol and polyvinylpyrolidone (-ve coefficient) showed -ve 


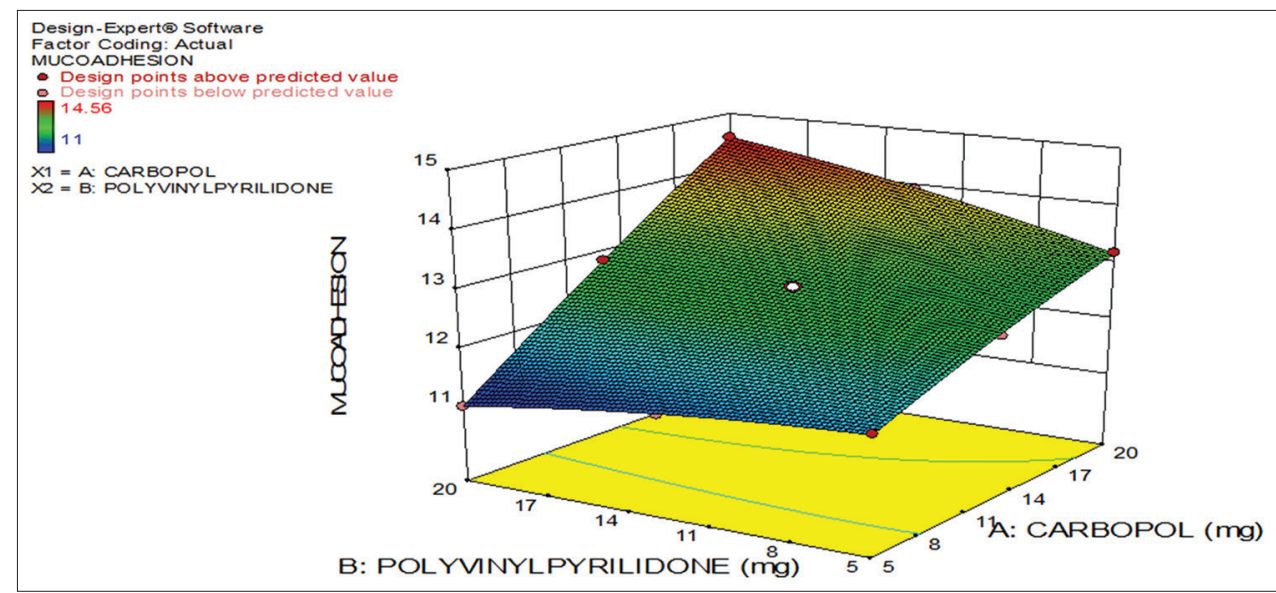

Fig. 14: 3D graph of mucoadhesion for tablet formulation

Table 17: Stability studies for buccal tablet

\begin{tabular}{|c|c|c|c|c|c|c|}
\hline No. of months & Hardness $\left(\mathrm{kg} / \mathrm{cm}^{2}\right)$ & Friability (\%) & \% Swelling & $\begin{array}{l}\text { Mucoad-hesive } \\
\text { strength (mg) }\end{array}$ & $\begin{array}{l}\text { Mucoadhesive } \\
\text { time (hr) }\end{array}$ & $\begin{array}{l}\text { In vitro drug release } \\
\text { study (\%) }\end{array}$ \\
\hline 1 & $3.2 \pm 0.01$ & $0.12 \pm 0.03$ & 42.18 & $12.82 \pm 0.32$ & More than $9.4 \mathrm{~h}$ & 99.65 \\
\hline 2 & $3.2 \pm 0.03$ & $0.12 \pm 0.01$ & 43.25 & $12.89 \pm 0.046$ & More than $9.4 \mathrm{~h}$ & 99.16 \\
\hline 3 & $3.2 \pm 0.02$ & $0.12 \pm 0.02$ & 43.38 & $12.72 \pm 0.062$ & More than $9.4 \mathrm{~h}$ & 99.25 \\
\hline 4 & $3.2 \pm 0.03$ & $0.12 \pm 0.01$ & 43.10 & $12.90 \pm 0.37$ & More than $9.3 \mathrm{~h}$ & 99.18 \\
\hline 5 & $3.2 \pm 0.0$ & $0.12 \pm 0.01$ & 43.32 & $12.45 \pm 0.086$ & More than $9.3 \mathrm{~h}$ & 99.84 \\
\hline 6 & $3.1 \pm 0.01$ & $0.11 \pm 0.02$ & 44.10 & $12.85 \pm 0.10$ & More than $9.4 \mathrm{~h}$ & 99.41 \\
\hline
\end{tabular}

sign it also indicated that drug delivery system gained more control over the release from prepared dosage form. From the equation for mucoadhesion, the information conveyed was: $\mathrm{R}^{2}$ was high indicating the adequate fitting of the quadratic model. As carbopol and polyvinylpyrolidone (+ve coefficient) showed +ve sign it also indicated that drug delivery system gained more mucoadhesion. Graphical presentation of data shows relationship between response and independent variables. The information given by graph was similar to that of mathematical equations obtained from statistical analysis. The response surface plots showed that various combinations of independent variables X1 and X2 satisfy specific requirement (i.e. drug release with mucoadhesion while taking into consideration of various factors involved in dosage form).

ANOVA for response surface quadratic model (For mucoadhesion study)

\section{In vivo study}

Six male New Zealand white rabbits $(2.6 \mathrm{~kg}$ ) were selected for the in vivo study. The dose of 5-FU was adjusted based on the rabbit weight and the optimized formulations were cut and placed in the buccal membrane with the help of a clip and tablets placed in the buccal membrane with the adhesive layer. The results are shown in Table 16.

\section{Stability study of optimized batch}

Stability study was done to see the effect of temperature and humidity on tablets and patches. Storage conditions:

1. Accelerated temperature $40^{\circ} \mathrm{C} \pm 2^{\circ} \mathrm{C}$

2. Accelerated temperature at $75 \% \mathrm{RH} \pm 5 \%$.

Time period of 6 months, at intervals of every 1 month, the tablets and patches were visually examined for any physical changes, changes in hardness, friability, swelling index, mucoadhesion strength, mucoadhesion time, and in vitro drug release study. The results indicate no significant change in the tablet properties. Hence, it can be concluded that the formulated buccal tablets are stable under appropriate storage conditions. The results for stability studies are shown in Table 17.

\section{CONCLUSION}

FTIR and DSC indicating compatibility of the drug and polymers in the tablet formulation and patch formulation at molecular level. The drug release of buccal tablet showed $75.10-99.34 \%$ and buccal patches showed 58.41-81.43\%. These formulations showed good results when compared to the conventional tablet. Formulation of mucoadhesive sustained release buccal tablets and patches of 5-FU successfully done using different polymers, which would definitely help in increasing

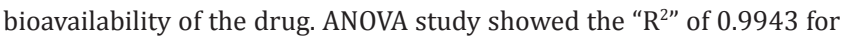
drug release and 0.9985 for swelling index is in reasonable agreement with the "Adj R-Squared" of 0.9849 for drug release and 0.9960 for swelling index. The ratio of 29.120 for drug release and 60.670 for swelling index indicates an adequate signal. The probablity value, i.e, $\mathrm{p}$ value found was also less than 0.0500 . Therefore, this model can be used to develop the design. The desirability result was found equal to 1 and hence, the results were found valid.

\section{CONFLICTS OF INTERESTS}

None.

\section{REFERENCES}

1. Mujoriya R, Dhamande K, Wankhede UR, Angure S. A review on study of buccal drug delivery system. Innov Syst Des Eng 2011;2:24-35.

2. Namita S, Garg MM. Current status of buccal drug delivery system: A review. J Drug Deliv Ther 2015;5:34-40.

3. Adhikari SN, Nayak BS, Nayak AK, Mohanty B. Formulation and evaluation of buccal patches for delivery of atenolol. AAPS Pharm Scitech 2010;11:1038-44.

4. Amul M, Meenakshi B, Deepak M, Harshna P. Buccal drug delivery system: A review. J Afr 2016;3:157-76.

5. Phanindra B, Moorthy BK, Muthukumaran M. Recent advances in mucoadhesive/bioadhesive drug delivery system: A review. Int J Pharm Med Biosci 2013;2:68-73.

6. Mamatha Y, Prasanth VV, Arunkumar S, Bhai MA, Yadav V. Buccal drug delivery a technical approach. J Drug Deliv Ther 2012;2:26-33.

7. Gavin A, Jimmy TH, Wang PD, Brownlow B, Bayoumi AT. Layered nano emulsions as mucoadhesive buccal systems for controlled delivery of oral cancer therapeutics. Int J Nano Med 2015;10:1569-84. 
8. Godbole NN, Galgatte UC, Chaudhari PD. Development and in-vitro evaluation of quantum dots as a carrier for delivery of 5-fluorouracil. Int J Pharm Pharm Sci 2016;8:289-96.

9. Rajendran R, Balan R, Ganesan N, Thiruvengadam D. Recent modalities in drug delivery via inhalation therapy-an advanced treatment strategy for pulmonary carcinoma. Int J Pharm Pharm Sci 2015;7:8-21.

10. British Medical Association. British National Formulary: BNF 69. $69^{\text {th }}$ ed. British Medical Association; 2015. p. 590

11. Airley R. Cancer Chemotherapy: Basic Science to the Clinic. Chichester: John Wiley \& Sons; 2009. p. 76.

12. Rossi S, editor. Australian Medicines Handbook. Adelaide: The Australian Medicines Handbook Unit Trust; 2013.

13. Joag MG, Sise A, Murillo JC, Sayed-Ahmed IO, Wong JR, Mercado C, et al. Topical 5-fluorouracil $1 \%$ as primary treatment for ocular surface squamous neoplasia. Ophthalmology 2016;12:1442-8.

14. Pendekal MS, Tegginamat PK. Development and characterization of chitosan-polycarbophil interpolyelectrolyte complex-based 5-fluorouracil formulations for buccal, vaginal and rectal application. DARU J Pharm Sci 2012;20:67.

15. Dhiman MK, Yedurkar PD, Sawant KK. Buccal bio adhesive delivery system of 5-fluorouracil: Optimization and characterization. Drug Dev Ind Pharm 2008;34:761-70.

16. Ghareeb MM, Mohammad HA. Study the effects of secondary polymers on the properties of buccoadhesive polyvinyl alcohol patches of 5-flourouracil. Int J Pharm Pharm Sci 2013;5:484-8.

17. Sharma YR. Elementary Organic Spectroscopy. $4^{\text {th }}$ ed. Delhi: S Chand \& Company Limited; 2007. p. 69-89.

18. Mutalik S, Naha A, Usha AN, Ranjith AK, Musmade P, Manoj K, et al. Preparation, in vitro, preclinical and clinical evaluations of once daily sustained release tablets of aceclofenac. Arch Pharm Res 2007;30:222-34

19. Patel DM, Shah PM, Patel CN. Formulation and evaluation of bioadhesive buccal drug delivery of repaglinide tablets. Asian J Pharm 2012;6:171-9.

20. Duchene D, Ponchel G. Bioadhesion of solid oral dosage forms, why and how? Eur J Pharm Biopharm 1997;44:15-23.

21. Li XQ, Ye ZM, Wang JB, Fan CR, Pan AW, Li C, et al. Mucoadhesive buccal films of tramadol for effective pain management. Rev Bras Anestesiol 2017;67:231-7.21

22. Rao TR, Hussain MA, Bharathi C, Shilpa A, Anjum M. Bioadhesive polymer buccal tablets for losartan potassium controlled delivery: Formulation, in-vitro and ex-vivo evaluation. Am J Alzheimer's Dis
Dement 2015;3:1-10.

23. Alagusundaram M, Chetty CM, Dhachinamoorthi D. Development and evaluation of novel trans-buccoadhesive bilayer tablets of famotidine: Asian J Pharm 2011:5:150-6.

24. Nafee NA, Ismail FA, Nabila A, Boraie LM. Mucoadhesive buccal patches of miconazole nitrate in vitro/in vivo performance and effect of ageing. Int J Pharm 2003;264:1-14.

25. Jaipal A, Pandey MM, Charde SY, Raut PP, Prasanth KV, Prasad RG. Effect of HPMC and mannitol on drug release and bioadhesion behavior of buccal discs of buspirone hydrochloride: In-vitro and in-vivo pharmacokinetic studies. Saudi Pharm J 2015;23:315-26.

26. Kaur A, Kaur G. Mucoadhesive buccal patches based on interpolymer complexes of chitosan-pectin for delivery of carvedilol. Saudi Pharm J 2012;20:21-7.

27. Bassi P, Kaur G. Polymeric films as a promising carrier for bioadhesive drug delivery: Development, characterization and optimization. Saudi Pharm J 2015;25:32-43

28. Ikram MD, Gilhotra N, Gilhotra RM. Formulation and optimization of mucoadhesive buccal patches of losartan potassium by using response surface methodology. Adv Biomed Res 2015;4:239.

29. Reddy JR, Muzib YI, Chowdary KP. Development and in-vivo characterization of novel transbuccal formulations of amiloride hydrochloride. J Pharm Res 2013;6:647-52

30. Shivanand K, Raju SA, Nizamuddin S, Jayakar B. In vivo bioavailability studies of sumatriptan succinate buccal tab. Daru 2011;19:224-30.

31. Gorle A, Patil P, Bhaskar R, Ola M. Development and evaluation of buccal film containing antihypertensive agent. Pharm Innov J 2015;4:53-60

32. Giannola LI, De Caro V, Giandalia G, Siragusa MG, Paderni C. 5-Flurourocil buccal tablets for locoregional chemotherapy of oral squamous cell carcinoma: Formulation, drug release and histological effects on reconstituted human oral epithelium and porcine buccal mucosa. Curr Drug Deliv 2010;7:109.

33. Sharma GK, Sharma PK, Bansal M. A review on mucoadhesive buccal patch as a novel drug delivery system. Pharm Sci Monitor Int J Pharm Sci 2016;4:1378-86.

34. Puratchikody A, Prasanth VV, Mathew ST, Kumar BA. Buccal drug delivery: Past, present and future-a review. Int J Drug Deliv 2011;3:171-84.

35. Nakagawa T, Kondo SI, Sasai Y, Kuzuya M. Preparation of floating drug delivery system by plasma technique. Chem Pharm Bull 2006;54:514-8. 